\title{
Alzheimer's disease - the experiences of national voluntary organisations
}

\author{
Brian O’Shea, Consultant Psychiatrist, Newcastle Hospital, Greystones, County \\ Wicklow, Ireland
}

I previously reported (O'Shea, 1989) on the experiences of national Huntington's disease (HD) organisations in Britain, Holland, Ireland, New Zealand, and the USA. The Australian experience was discussed later (Kapp, 1990; O'Shea, 1990). The earlier paper supported the contention (Black, 1988) that the medical profession in general was not supportive of HD voluntary groups. I also expressed concern that the lobbying of voluntary groups representing far more common disorders was "bound to dilute the impact that Huntington societies may have."

I have now replicated the HD study, this time on national Alzheimer organisations, using a slightly modified postal questionnaire.

\section{The study}

Contact persons (supplied by the Alzheimer Society of Ireland - ASI) in 20 countries were sent a detailed questionnaire and covering letter. They were asked to supply historical, financial, social, and epidemiological information relating to their own countries, information on their relations with professionals and politicians, and on services available to patients with Alzheimer's disease (AD). The chairman of ASI (Michael M. Coote), who was also chairman of the European organisation, was kind enough to support the project at a meeting of Alzheimer Europe in September 1991.

\section{Findings}

Only six $(30 \%)$ countries responded after 10.5 months despite repeated attempts: Ireland, Scotland, England (also covers Wales and Northern Ireland), Australia, New Zealand (NZ) and the Netherlands. Apart from North America, the vast majority of the English-speaking world was represented by the replies received.

The oldest of these six national organisations is England (1979) and the youngest is Scotland (1988 previously part of the English group). Both southern hemisphere countries had local AD groups three years older than their national organisations. The English, Irish, and Scottish groups were founded by women; the Australian organisation was born by the

joining together of the six state associations; the NZ organisation was started by a group of people in Christchurch; and a Dutch geriatrician and his wife founded their national association. Although each national organisation was associated with a variable number of other organisations, Alzheimer's Disease International is the major umbrella group. Five of the countries replying had national, regional, and local groups, whereas the Dutch association, or 'Stichting', is centrally focused.

Funding in each case came from a mixture of state grants, voluntary donations and social events. Smaller amounts of money came from membership fees and the sale of brochures. Only two countries gave a detailed breakdown of funds. Alzheimer's Scotland's finances are derived in the following proportions: health boards $(29 \%)$, local authorities $(21 \%)$, Scottish Office $(18 \%)$, fund raising $(14 \%)$, major trusts $(8 \%)$, industry/commercial $(8 \%)$, and charges $(4 \%)$. Voluntary donations from individual and corporate sources in England amounted to $£ 1.5$ million; there is also an income from events and grants, e.g. $£ 100,000$ per annum from the Department of Health.

Support from the medical profession was perceived as generally good to fair, with much more commitment from some interested individuals and medical organisations. Political support was viewed as more often fair than poor, with the exception of New Zealand where it was seen as good. The Irish saw politicians as giving mainly verbal support, whereas the English drew a distinction between fair domestic policy-making and a disinclination to part with money.

Attendance at meetings is highest in England and $\mathrm{NZ}$, low in Ireland, and varies widely with circumstances (e.g. location, programme, and national v. local) in the others. Reasons for a good attendance included good publicity in NZ. In Ireland it was felt that carers were too tied to their charges to be able to attend. As with HD associations, patients usually do not attend meetings of AD organisations. Apart from NZ and Holland, national AD groups currently give financial support to medical research $(£ 70,000$ per annum in England).

Respondents differed widely regarding estimates of where terminal care for AD occurs; all mention 
nursing homes, whereas psychiatric and general hospitals, and the patients' own homes are mentioned by different organisations, e.g. Ireland states that $\mathrm{AD}$ cases do not spend their last days in psychiatric institutions, a statement which flies in the face of common experience. Respondents may have interpreted this question to mean "Where would you like patients to end their days?", rather than "Where do the majority of Alzheimer cases in your country end their days?" (followed by various choices and an 'other' category), as appeared in the questionnaire. Certainly, HD organisations would prefer care in non-psychiatric facilities (O'Shea, 1989). Stigma associated with $A D$ was seen as stemming from ignorance, lack of a cure, an age bias, and psychiatric connotations, although this was seen as improving, largely as a result of publicity. The past 20 years have seen improvements due (the respondents reported) to the influence of AD organisations, increased emphasis on home care, support for carers, and improved understanding of brain dysfunction. The next 20 years, it was hoped, would show further advances in these areas, and improved funding for respite care.

Only the Dutch respondent felt that an adequate genetic counselling service was available. The Scottish Director reported that there was a service in two major cities, but believed it was not appropriate for the vast majority of cases, a reference to the small number of definite heredofamilial cases. A wide variety of support services were mentioned by each country, but the Irish respondent felt that "statutory services are negligible". Official support for carers was viewed as good in Australia, less so in Holland and NZ, poor in England and Scotland, and almost non-existent in Ireland. Support for sufferers from AD by their offspring was reported universally as good to excellent, especially when they understand the problem, although the Scottish respondent recorded that only a minority of carers are the patients' children.

The percentage of the national population reported to be over 65 years averaged 11.5 , range 11 (Ireland and Australia) to 15 (England). The percentage of cases of $\mathrm{AD}$ commencing before that age averaged 9, range 0.01 (England) to 20 (Ireland), with NZ registering “don't know".

\section{Comment}

There are clear similarities between the reports of AD and HD organisations, such as lack of money and support from only a small fraction of the medical profession, with a remarkable sameness in their view of politicians. Both types of organisation suffer from lukewarm attendance at meetings, and women have been the initial source of enthusiasm for most groups. The NZ National Co-Ordinator pointed out that many cases do not have AD at autopsy, while my experience is that people whose relatives have different diseases tend to attend AD meetings, probably for the support they offer and lack of information on more appropriate organisations. The Dutch organisation felt that home services were being neglected at the expense of institutional care, and the Irish Chairman was scathing of primary care physicians and central and local authorities.

On the positive side, most national groups held out hopes for the next generation of sufferers. In Ireland, the Alzheimer Society has commenced lectures to senior medical students in one of Dublin's medical schools, and both public health nurses and social workers give excellent support, despite the long hours and poor pay involved.

\section{Acknowledgements}

I wish to thank Michael M. Coote (Ireland), Ewan Davidson (Scotland), Noreen Siba (England), J. H. van der Poel (Netherlands), Jan Harrison (New Zealand), and Henry Brodety and Pat Jones (Australia). Bristol-Myers Squibb(Michael Dempsey) funded the project.

\section{References}

BLACK, M. E. (1988) Self help groups and professionals what is the relationship? British Medical Journal, 296, 1485-1486.

KAPP, R. (1990) Huntington's disease associations in Australia. Psychiatric Bulletin, 14, 93-94.

O'SHEA, B. (1989) Huntington's disease - the experiences of voluntary organisations. Psychiatric Bulletin, 13, 409-411. - (1990) Huntington's disease associations in Australia. Psychiatric Bulletin, 14, 94. 